\title{
Nurses' Knowledge, Practice, and Confidence after the Training Program on Wound Care at the Agriculture General Hospital in Vietnam
}

\author{
Phan Thi Dung1,2,3, Le Thi Trang ${ }^{4}$, Ha Huu Tung5 \\ ${ }^{1}$ Nursing Office, Thien An Obstetrics and Gynecology Hospital, Hanoi, Vietnam \\ ${ }^{2}$ Faculty of Nursing, Hanoi University of Business and Technology, Hanoi, Vietnam \\ ${ }^{3}$ Nursing Office, Viet Duc University Hospital, Hanoi, Vietnam \\ ${ }^{4}$ Faculty of Nursing, Da Nang University of Medical Technology and Pharmacy, Danang, Vietnam \\ ${ }^{5}$ Director Office, General Hospital of Agricultural, Hanoi, Vietnam \\ Email: phanthidzungvd@gmail.com, letrangyte2@gmail.com, hahuutung.200564@gmail.com
}

How to cite this paper: Dung, P.T., Trang, L.T. and Tung, H.H. (2020) Nurses' Knowledge, Practice, and Confidence after the Training Program on Wound Care at the Agriculture General Hospital in Vietnam. Open Journal of Nursing, 10, 646-656. https://doi.org/10.4236/ojn.2020.106045

Received: May 29, 2020

Accepted: June 27, 2020

Published: June 30, 2020

Copyright ( 2020 by author(s) and Scientific Research Publishing Inc. This work is licensed under the Creative Commons Attribution International License (CC BY 4.0).

http://creativecommons.org/licenses/by/4.0/ (c) (i) Open Access

\begin{abstract}
Aims: Wound care is the basic technique in patient care which has direct effects on treatment outcome. However, the Agriculture General Hospital (AGH), Vietnam, has never organized a continuing professional development (CPD) training program based on Vietnam's Basic Nursing Competency Standards (VNBNCS) for their nurses. This study aimed to examine the knowledge, practice, and confidence level among nurses at the AGH after 12 months of implementing a VNBNCS-based wound care training program. Methodology: This descriptive and comparative study assessed the changes in knowledge, practice, and confidence scores of 43 nurses at five clinical departments before and 12 months after the training program (April 2018 to June 2019). Data were collected using a self-administrated knowledge questionnaire with 48 items, a 13 -item confidence checklist, and a 16-item skills checklist. EpiData 3.1 and SPSS 18.0 were used to enter and analyze data, respectively. Results: The mean scores of knowledge (113.70 \pm 14.75 vs. $129.7 \pm$ $19.6)$, and practice $(63.21 \pm 19.99$ vs. $132.07 \pm 4.31)$ statistically significantly increased 12 months after training $(p<0.001)$. The mean score of confidence in performing wound care increased in all of the 13 aspects $(p<0.001)$. Conclusion: Nurses' wound care-related knowledge, practice, and confidence have improved 12 months after training. This demonstrates the VNBNCS-based wound care training program developed by Viet Duc University Hospital is suitable for use in the AGH and has achieved its promising initial outcomes. This program should be duplicated in other health facilities.
\end{abstract}




\section{Keywords}

Nurses, Wound Care, Knowledge, Practice, Training

\section{Introduction}

Wound care is the basic technique in patient care which has direct effects on treatment outcomes [1] [2]. In Britain, 3\% of the total health budget is dedicated to wound care, equivalent to $2.3-3.1$ billion pounds per year [3]. In the United States of America, about 5.7 million people suffered from chronic wounds while complications, bacterial infections, amputations, and pressure ulcers could be prevented if chronic wounds were well cared and managed at early stages [4]. In 2012, the "Vietnam's Basic Nursing Competency Standards" (VNBNCS) was approved by Vietnam's Ministry of Health [5]. Viet Duc University Hospital is the first hospital to develop a wound care training program based on these Standards, and the effectiveness of the program was examined in two articles by Phan et al. in 2014 and 2017. According to the former study, the knowledge and practice scores of nurses significantly improved after 12 months of training [6]. The latter study suggested that the rate of nurses with adequate practice competency increased after training, and that the NCS-based wound care training program was effective in improving nurses' competency [7].

The Agriculture General Hospital (AGH) is a first-rank hospital with 500 patient beds, adequate infrastructure, and advanced equipment. In the AGH, about 15 surgical operations are performed, and 150 wounds are tended by nurses on a daily basis. In April 2018, the hospital surveyed nurses at five clinical departments about their knowledge, practice and confidence regarding VNBNCS-based wound care. The AGH has never organized a VNBNCS-based continuing professional development (CPD) training program for nurses although Vietnam's Law on medical examination and treatment specifies that each health work should receive at least 48 hours of continuous training per year. Based on the results of the pre-training survey, the hospital conducted training for nurses using Viet Duc University Hospital's training program and materials. Therefore, this study aimed to examine the VNBNCS-based wound care knowledge, practice, and confidence among nurses at five clinical departments of the AGH 12 months after training.

\section{Materials and Methods}

\subsection{Study Population}

Our present study recruited all of the 43 nurses directly taking care of patients. These nurses had participated in the pre-training survey and the continuous training program on VNBNCS-based wound care. Their participation in the post-training survey was also voluntary. 


\subsection{Methods}

This descriptive and comparative study was conducted on 43 nurses at five clinical departments of the AGH from April 2018 to June 2019. In 2017, Vietnam's Ministry of Health promulgated the Decision No. 144/QD-K2DT regarding the issuance of the continuous training program and materials on wound care [8]. The AGH provided training for the nurses based on this training program, including taught sessions and self-study, and these materials. The taught sessions consisted of 11 theoretical hours and 24 practical hours, and the self-study duration for each nurse was 16 days ( 8 hours/day). Nurses participated in the pre-training survey and the post-training survey which was conducted 12 months after the nurses attended the program. The effectiveness of the training program was assessed by comparing mean scores of knowledge, practice, and confidence between the two surveys.

We used a questionnaire and two checklists by Phan et al. [6] [7]. The self-administered knowledge questionnaire included 10 sections with a total of 48 questions (correct option $=1$ point; incorrect option $=0$ point; the maximal total knowledge score was 167 points). The practice observation checklist was used to score the nurses' wound care performance. Sixteen items in the checklist were assessed using a 1 - 10 point scale, with higher scores indicating more advanced levels of wound care skills (the minimal and maximal practice scores were 10 and 160 points, correspondingly). The self-administered checklist on nurses' confidence in performing wound care consisted of 13 questions assessed using a 5 -point Likert scale ( $1=$ very not confident; $2=$ not confident; $3=$ neutral; $4=$ confident; and $5=$ very confidence). The level of confidence in performing wound care was reflected by the mean score of 13 questions. The Cronbach's alpha was calculated to be 0.73 .

Data were entered and analyzed using EpiData 3.1 and SPSS 18.0, respectively. Data were presented as frequencies and percentages for continuous variables or means \pm standard deviations (SD) for categorical variables. The paired $t$-test was used to analyze the differences between mean scores of knowledge, practice, and confidence.

\subsection{Ethical Considerations}

This study was an institutional-level scientific research which received the AGH's approval on December 21, 2018. All of the nurses voluntarily participated in the study and were entitled to withdraw from the study at any time. Their personal information was kept confidential and only served the objectives of this study.

\section{Results}

\subsection{Characteristics of Study Participants}

Table 1 shows that 43 nurses participated in both pre- and post-training surveys. They had a mean age of $32.56 \pm 6.06$ years and employment duration of 
Table 1. Characteristics of study participants.

\begin{tabular}{lcc}
\hline \multicolumn{1}{c}{ Characteristics } & \multicolumn{2}{c}{ Nurses $(\mathbf{n}=43)$} \\
\cline { 2 - 3 } & Frequency & Percentage (\%) \\
\hline Mean Age, mean \pm SD, years & $32.56 \pm 6.06$ \\
Employment duration, mean \pm SD, years & $9.35 \pm 6.48$ \\
Education level & 7 & 16.3 \\
$\quad$ University & 11 & 25.6 \\
College & 24 & 55.8 \\
Secondary & 1 & 2.3 \\
Primary & & 16.3 \\
Seniority & 7 & 48.8 \\
$<5$ years & 21 & 34.9 \\
5 - 10 years & 15 & \\
$>10$ years & & 67.4 \\
Attended wound care training courses/workshops & 29 & 32.6 \\
Yes & 14 & \\
No & & \\
\hline
\end{tabular}

$9.35 \pm 6.48$ years. Almost all nurses had worked for $\geq 5$ years whereas $16.3 \%$ of nurses had $<5$ years of work experience. Nurses with secondary, college, and university education accounted for 55.8\%, 25.6\%, and $16.3 \%$, respectively. Besides, 29 out of $43(67.4 \%)$ nurses used to attend training courses or workshops on wound care. However, no nurse described training courses or workshops in detail.

\subsection{Wound Care Knowledge before and 12 Months after Training}

The nurses' mean total knowledge score increased by 15.76 points, from 113.70 \pm 14.75 in the pre-training survey to $129.7 \pm 19.6$ in the post-training survey ( $p<$ $0.001)$. However, the differences in the mean knowledge score were statistically significant $(p<0.001)$ in only six out of ten knowledge sections, including general wound care, infection control, health education for patients, clean wound care, exuding wound care, and pressure ulcer care. The knowledge of the other four sections, namely communication with patients, career management and development, infected wound care, and suturing technique, did not improve significantly 12 months after training (Table 2).

\subsection{Wound Care Practice before and 12 Months after Training}

The study results show that the mean total practice score increased by 68.86 points, from $63.21 \pm 19.99$ points in the pre-training survey to $132.07 \pm 4.31$ in the post-training survey $(p<0.001)$. The increase in the practice scores in all of the 16 sections was statistically significant. The largest increase was found for the skill of monitoring and evaluating pain and bleeding in patients (6.62 points), 
Table 2. Knowledge score before and 12 months after training $(\mathrm{n}=43)$.

\begin{tabular}{|c|c|c|c|c|}
\hline \multirow[b]{2}{*}{ Type of Knowledge } & \multicolumn{2}{|c|}{ Mean scores (mean $\pm S D$ ) } & \multirow{2}{*}{$\begin{array}{c}\text { Difference } \\
\text { between mean } \\
\text { scores }(95 \% \mathrm{CI})\end{array}$} & \multirow[b]{2}{*}{$p$} \\
\hline & $\begin{array}{l}\text { Before } \\
\text { training }\end{array}$ & $\begin{array}{l}\text { After } \\
\text { training }\end{array}$ & & \\
\hline $\begin{array}{l}\text { General knowledge of wound care } \\
\text { (44 points) }\end{array}$ & $31.49 \pm 3.67$ & $36.19 \pm 3.64$ & $4.69(3.58-5.82)$ & $<0.001$ \\
\hline $\begin{array}{l}\text { Infection control in wound care } \\
\text { (10 points) }\end{array}$ & $5.40 \pm 1.07$ & $6.81 \pm 1.76$ & $1.41(0.87-1.96)$ & $<0.001$ \\
\hline $\begin{array}{l}\text { Communication with patients } \\
\text { (17 points) }\end{array}$ & $11.21 \pm 2.56$ & $12.95 \pm 3.37$ & $1.74(0.71-2.8)$ & 0.002 \\
\hline $\begin{array}{l}\text { Health education for patients } \\
\qquad(10 \text { points })\end{array}$ & $7.26 \pm 1.26$ & $8.37 \pm 1.56$ & $1.11(0.63-1.59)$ & $<0.001$ \\
\hline $\begin{array}{l}\text { Career management and } \\
\text { development ( } 32 \text { points })\end{array}$ & $22.42 \pm 5.35$ & $24 \pm 5.92$ & $1.58(-0.24-3.40)$ & 0.088 \\
\hline Clean wound care (2 points) & $1 \pm 0$ & $1.86 \pm 0.35$ & $0.86(0.75-0.97)$ & $<0.001$ \\
\hline Infected wound care ( 20 points) & $14.49 \pm 2.66$ & $15.51 \pm 3.43$ & $1.02(-0.03-2.08)$ & 0.058 \\
\hline Suture technique (14 points) & $10.21 \pm 2.04$ & $10.93 \pm 2.28$ & $0.72(0.02-1.42)$ & 0.45 \\
\hline Exuding wound care (8 points) & $3.93 \pm 1.44$ & $5.35 \pm 1.39$ & $1.42(0.99-1.85)$ & $<0.001$ \\
\hline Pressure ulcer care (10 points) & $6.30 \pm 1.44$ & $7.49+1.76$ & $1.19(0.65-1.73)$ & $<0.001$ \\
\hline Total score (167) & $113.70 \pm 14.75$ & $129.7 \pm 19.6$ & $15.76(9.73-21.8)$ & $<0.001$ \\
\hline
\end{tabular}

followed by the appropriate and adequate documentation of medical records (5.58 points), patient assessment (5.07 points), strict compliance with disinfection and sterilization principles (4.65 points), wound assessment (4.26 points), and communication with patients during wound care (2.23 points) (Table 3 ).

\subsection{Confidence in Performing Wound Care before and 12 Months after Training}

Nurses felt more confident in practicing wound care after 12 months of training. The mean confidence score statistically significantly increased in all of the 13 skills $(p<0.001)$, especially in problem identification ( 1.42 points), planning (1.35 points), and decision-making (1.33 points). The smallest increase was observed in patient assessment ( 0.95 points) (Table 4$)$.

\section{Discussion}

Training in wound care knowledge and practice helps improve wound care outcomes, reduce treatment costs, and lower the recurrence of wounds [9]. Knowledge has been demonstrated to influence practice while practice and self-experience help learners memorize the knowledge they acquire [10] [11]. Peter Lewis et al. suggested that nurses' characteristics and needs should be surveyed before training [12]. Besides, the training program should consider the results of the pre-training survey to identify the aspects of knowledge that need improving 
Table 3. Skill score before and 6 months after the training program $(n=43)$.

\begin{tabular}{|c|c|c|c|c|}
\hline \multirow[b]{2}{*}{ Skills } & \multicolumn{2}{|c|}{ Mean scores (mean $\pm \mathrm{SD}$ ) } & \multirow{2}{*}{$\begin{array}{c}\text { Difference } \\
\text { between mean } \\
\text { scores }(95 \% \mathrm{CI})\end{array}$} & \multirow[b]{2}{*}{$p$} \\
\hline & $\begin{array}{c}\text { Before } \\
\text { training }\end{array}$ & $\begin{array}{c}\text { After } \\
\text { training }\end{array}$ & & \\
\hline \multicolumn{5}{|l|}{ Assessing skills } \\
\hline Assessing patients & $3.09 \pm 2.49$ & $8.16 \pm 0.84$ & $5.07(4.81-5.33)$ & $<0.001$ \\
\hline Assessing wounds & $4.28 \pm 2.19$ & $8.53 \pm 0.7$ & $4.26(4.04-4.47)$ & $<0.001$ \\
\hline $\begin{array}{l}\text { Ensuring the adequacy, } \\
\text { readiness, and appropriateness } \\
\text { of medical equipment }\end{array}$ & $4.37 \pm 2.11$ & $8.6 \pm 0.85$ & $4.23(3.97-4.50)$ & $<0.001$ \\
\hline \multicolumn{5}{|l|}{ Wound care planning skills } \\
\hline Planning proper wound care & $3.91 \pm 1.74$ & $7.95 \pm 0.65$ & $4.04(3.84-4.24)$ & $<0.001$ \\
\hline $\begin{array}{l}\text { Ensuring that patients are } \\
\text { well prepared to receive } \\
\text { medical procedures }\end{array}$ & $4.88 \pm 1.18$ & $8.16 \pm 0.62$ & $3.28(3.09-3.47)$ & $<0.001$ \\
\hline \multicolumn{5}{|l|}{$\begin{array}{l}\text { Performing the wound } \\
\text { care procedure }\end{array}$} \\
\hline $\begin{array}{l}\text { Introducing themselves and } \\
\text { explaining to patients about } \\
\text { what are to be done }\end{array}$ & $4.05 \pm 2.63$ & $8.28 \pm 0.85$ & $2.23(3.97-4.49)$ & $<0.001$ \\
\hline $\begin{array}{l}\text { Changing dressings safely } \\
\text { and properly }\end{array}$ & $4.17 \pm 2.01$ & $8.16 \pm 0.72$ & $3.99(3.77-4.21)$ & $<0.001$ \\
\hline $\begin{array}{l}\text { Strictly following the disinfection } \\
\text { and sterilization principles }\end{array}$ & $3.53 \pm 2.05$ & $8.19 \pm 0.63$ & $4.65(4.46-4.85)$ & $<0.001$ \\
\hline $\begin{array}{l}\text { Preparing proper medical } \\
\text { equipment for wound care }\end{array}$ & $5.05 \pm 1.41$ & $8.21 \pm 0.67$ & $3.16(2.95-3.37)$ & $<0.001$ \\
\hline $\begin{array}{l}\text { Ensuring the work environment } \\
\text { is safe and private }\end{array}$ & $3.95 \pm 2.02$ & $8.19 \pm 0.74$ & $4.24(4.01-4.47)$ & $<0.001$ \\
\hline $\begin{array}{l}\text { Communicating with patients } \\
\text { while taking care of their wounds }\end{array}$ & $4.30 \pm 2.54$ & $8.35 \pm 0.61$ & $4.05(3.86-4.24)$ & $<0.001$ \\
\hline $\begin{array}{l}\text { Ensuring each step of the } \\
\text { procedure is performed within } \\
\text { the specified length of time }\end{array}$ & $4.16 \pm 1.86$ & $8.07 \pm 0.63$ & $3.91(3.72-4.10)$ & $<0.001$ \\
\hline $\begin{array}{l}\text { Completing the wound care } \\
\text { procedure and making sure } \\
\text { patients feel comfortable }\end{array}$ & $4.91 \pm 1.95$ & $8.37 \pm 0.62$ & $3.46(3.27-3.65)$ & $<0.001$ \\
\hline $\begin{array}{l}\text { Cleaning up medical equipment } \\
\text { used for wound care }\end{array}$ & $4.42 \pm 2.10$ & $8.3 \pm 0.56$ & $3.88(3.71-4.05)$ & $<0.001$ \\
\hline \multicolumn{5}{|l|}{$\begin{array}{c}\text { Medical record } \\
\text { documentation skills }\end{array}$} \\
\hline $\begin{array}{l}\text { Documenting medical records } \\
\text { appropriately and adequately }\end{array}$ & $2.72 \pm 2.86$ & $8.3 \pm 0.67$ & $5.58(5.37-5.79)$ & $<0.001$ \\
\hline $\begin{array}{l}\text { Monitoring and assessing patients' } \\
\text { pain and bleeding after wound care }\end{array}$ & $1.47 \pm 2.67$ & $8.09 \pm 0.53$ & $6.62(6.46-6.78)$ & $<0.001$ \\
\hline Total score (160 points) & $63.21 \pm 19.99$ & $132.07 \pm 4.31$ & $68.86(67.52-70.21)$ & $<0.001$ \\
\hline
\end{tabular}


Table 4. Confidence score before and 12 months after training $(n=43)$.

\begin{tabular}{|c|c|c|c|c|c|}
\hline \multirow[b]{2}{*}{ No. } & \multirow[b]{2}{*}{ Basic skills } & \multicolumn{2}{|c|}{ Mean scores (mean $\pm \mathrm{SD})$} & \multirow{2}{*}{$\begin{array}{c}\text { Difference } \\
\text { between mean } \\
\text { scores }(95 \% \mathrm{CI})\end{array}$} & \multirow[b]{2}{*}{$p$} \\
\hline & & $\begin{array}{l}\text { Before } \\
\text { training }\end{array}$ & $\begin{array}{l}\text { After } \\
\text { training }\end{array}$ & & \\
\hline 1 & Communication skills & $3.14 \pm 0.52$ & $4.19 \pm 0.39$ & $1.05(0.88-1.21)$ & $<0.001$ \\
\hline 2 & Assessing patients & $3.12 \pm 0.5$ & $4.07 \pm 0.34$ & $0.95(0.84-1.07)$ & $<0.001$ \\
\hline 3 & Assessing wounds & $2.88 \pm 0.63$ & $4.14 \pm 0.47$ & $1.26(1.02-1.50)$ & $<0.001$ \\
\hline 4 & Identifying wound care problems & $2.79 \pm 0.56$ & $4.21 \pm 0.51$ & $1.42(1.24-1.59)$ & $<0.001$ \\
\hline 5 & Planning wound care & $2.81 \pm 0.5$ & $4.16 \pm 0.53$ & $1.35(1.19-1.51)$ & $<0.001$ \\
\hline 6 & Making wound care decisions & $2.79 \pm 0.52$ & $4.12 \pm 0.53$ & $1.33(1.17-1.49)$ & $<0.001$ \\
\hline 7 & Performing clean wound care & $2.95 \pm 0.58$ & $4.23 \pm 0.48$ & $1.28(1.14-1.42)$ & $<0.001$ \\
\hline 8 & Performing infected wound care & $2.76 \pm 0.58$ & $4.05 \pm 0.44$ & $1.29(1.13-1.44)$ & $<0.001$ \\
\hline 9 & Performing exuding wound care & $2.9 \pm 0.53$ & $4.1 \pm 0.57$ & $1.19(1.02-1.36)$ & $<0.001$ \\
\hline 10 & Performing pressure ulcer care & $2.81 \pm 0.45$ & $4 \pm 0.5$ & $1.19(1.05-1.33)$ & $<0.001$ \\
\hline 11 & $\begin{array}{l}\text { Changing dressings based on } \\
\text { the related procedure }\end{array}$ & $3.05 \pm 0.43$ & $4.19 \pm 0.45$ & $1.14(0.97-1.31)$ & $<0.001$ \\
\hline 12 & $\begin{array}{l}\text { Giving health instructions, } \\
\text { counseling, education to patients }\end{array}$ & $3.02 \pm 0.34$ & $4.14 \pm 0.35$ & $1.12(1.02-1.22)$ & $<0.001$ \\
\hline
\end{tabular}

and create favorable conditions for nurses to improve their practice of wound care. In this present study, our continuous training program involved both theoretical and practical sessions.

\subsection{Wound Care Knowledge before and 12 Months after Training}

Twelve months after training, the mean knowledge score increased in all aspects, especially the general knowledge of wound care (4.69 points). This indicated that the training program had a positive effect on nurses' knowledge on wound care. The mean knowledge score improved significantly in only six aspects of knowledge, namely general wound care, infection control, health education for patients, clean wound care, exuding wound care, and pressure ulcer care. However, the other four aspects show no significant differences after training (i.e., communication, career management and development, infected wound care, and suturing technique). This may result from the nurses' lack of opportunities to experience these aspects in practice. Therefore, future workshops and training courses should help nurses better understand the importance of these knowledge aspects. Previous studies showed that clinical experience before and after training helped improve nurses' knowledge and skills [13] [14] [15], and education contributed to improving their knowledge, attitude, and skills related to wound care [16].

\subsection{Wound Care Practice before and 12 Months after Training}

Our study results showed that the mean scores in all 16 aspects of wound care 
practice statistically significantly improved after 12 months of training. Before training, nurses scored relatively low in aspects such as patient assessment, medical record documentation, and monitoring and assessment of patients' pain and bleeding after wound care. However, their practice of wound care became better after 12 months of training, especially when it came to monitoring and assessment of pain and bleeding after wound care (6.62 points). The scores for medical record documentation, patient assessment, and strict compliance with disinfection and sterilization principles increased by 5.58, 5.07, and 4.65 points, respectively. Patient assessment plays an essential role in the provision of comprehensive care. Particularly, assessments conducted within several days after surgical operations are crucial to the timely detection of pain and bleeding. Based on these assessments, healthcare teams can customize wound care plans for patients and provide them with effective and high-quality services. The World Health Organization (WHO) and the United Nations (UN) consider access to pain treatment as a fundamental human right and one of the fundamental objectives of today's health care [17]. Previous studies revealed that nurses had poor knowledge and attitude toward pain management [18] while pain management is a challenge to every health care facility [19]. Therefore, they should be continuously trained in knowledge and attitude regarding pain management [20] [21].

Our study results showed that in the pre-training survey, nurses had the lowest score of practice in pain and bleeding management ( $1.47 \pm 2.67$ points). Being aware of this weakness, nurses in our study paid more attention to this aspect and used the pain assessment scale about which they were instructed during the training program. Accordingly, their mean score increased in the post-training survey $(8.09 \pm 0.53$ points). With regard to medical record documentation, Vietnam's Ministry of Health specifies it as one of the 12 tasks of nurses [22]. The proper and timely documentation of medical records can assist nurses in making wound care decisions. The mean score for medical record documentation in the pre-training survey was $2.72 \pm 2.86$ points. Both trainees and trainers realized and therefore focused on overcoming this weakness. Thanks to this, the mean score of practice in the aspect increased by $8.30 \pm 0.67$ points over 12 months. This result is consistent with those in two studies by Phan et al. [23] [24] at Viet Duc University Hospital which showed that practical sessions in the program were suited for nurses. Twelve months after training, nurses in our study had built up good habits and skills of wound care using the wound care procedure acquired from the training program. The reasons behind their improvements might be that they had well-defined, specific, and feasible objectives, and experienced a learning process based on real situations [25].

\subsection{Confidence in Performing Wound Care before and 12 Months after Training}

In our study, the nurses' level of confidence in practicing 13 basic skills of wound care improved significantly after 12 months of training $(p<0.001)$. This 
indicates that the continuous training program was suitable for their needs and wound care specialties. Our study results were consistent with those from two previous assessments of the wound care training program conducted at Viet Duc University Hospital by Phan et al. in 2016 [24] and 2018 [23]. These two studies also showed that the confidence of nurses increased in 12 out of 13 skills thanks to the training program. The mean score for problem identification was found highest $(2.79 \pm 0.56$ points in the pre-training survey vs. $4.21 \pm 0.51$ points in the post-training survey), followed by wound care planning skills ( $2.81 \pm 0.50$ vs. $4.16 \pm 0.53)$, and wound care decision-making skills ( $2.79 \pm 0.52$ vs. $4.12 \pm 0.53)$. The training program helped nurses better understand the status of wounds and improved their ability to choose proper methods and medical equipment to manage complicated wounds, thereby increasing their confidence level. This result is affirmed by the theory proposed by Bandura [26] on the influence of confidence on the ability to handle diverse and complex situations. As the nurses experienced the effectiveness of the program during their learning process and had their wound care performance monitored and assessed at 3,6, and 9 months after training, their confidence in providing wound care for patients at 12 months was improved. An increase of only 0.95 points was seen in their confidence in patient identification skills $(3.12 \pm 0.50$ points in the pre-training survey vs. $4.07 \pm 0.34$ points in the post-training survey). Meanwhile, the highest scores were found in assessing skills (5.07, 4.26, and 4.23 points).

The strength of the study lies in its prospective nature. However, it has some limitations that need to be addressed. First, it had a small sample size of 43 nurses. Second, the study used a self-administered knowledge questionnaire, which possibly led to bias. Finally, we could not establish an association of confidence with knowledge and practice. Therefore, future studies with large sample sizes and longer terms are required to further increase the validity of the study results and focus on examining whether nurses' level of confidence is linked with their knowledge and practice.

\section{Conclusion}

Nurses' knowledge, practice, and confidence related to wound care improved after 12 months of training. This demonstrates that the wound care VNBNCS-based training program developed by Viet Duc hospital is effective in improving the nurses' wound care competencies and is suitable for use in the AGH. This training program should target nurses directly in charge of wound care in other health facilities. Future research should focus on examining the associations of confidence, knowledge, and practice with factors affecting wound care, thereby informing suitable interventions that aim to improve the quality of wound care.

\section{Acknowledgements}

We would like to give our special thanks to Mr. Ha Huu Tung-the Director of the Agriculture General Hospital, as well as leaders and staff at five clinical de- 
partments at the hospital, for supporting and creating favorable conditions for us to conduct this study.

We are also indebted to our colleagues for their enthusiastic support and exchange of experience with us during our conduct of this study.

\section{Conflicts of Interest}

The authors declare to have no conflicts of interest.

\section{References}

[1] Dealey, C. (2005) The Care of Wounds: A Guide for Nurses. Blackwell Publishing Ltd., Hoboken. https://doi.org/10.1002/9780470774946

[2] Meaume, S., et al. (2012) Management of Chronic Wounds with an Innovative Absorbent Wound Dressing. Journal of Wound Care, 21, 315-316, 318, 320-322. https://doi.org/10.12968/jowc.2012.21.7.315

[3] Drew, P., Posnett, J. and Rusling, L. (2007) The Cost of Wound Care for a Local Population in England. International Wound Journal, 4, 149-155. https://doi.org/10.1111/j.1742-481X.2007.00337.x

[4] Macdonald, J.M. and Ryan, T.J. (2010) Global Impact of the Chronic Wound and Lymphoedema. Health Organization, Geneva, 13-24.

[5] Vietnam's Ministry of Health (2012) Decision No. 1352/QD-BYT on Issuance of Basic Competency Standards for Vietnamese Nurses.

[6] Phan, T.D., et al. (2014) Assessment of Knowledge, Attitude, and Practice of Wound Care among Nurses Based on Nursing Competencies Standards and Some Related Factors. Journal of the Vietnamese Association of Orthodontists, 368-373.

[7] Phan, T.D., et al. (2017) Effectiveness of Training Programme on Nurses' Wound Care Competencies after One Year of Implementation. The Thai Journal of Surgery, 38, 140-146.

[8] Vietnam's Ministry of Health (2017) Decision No. 144/QD-K2DT Regarding the Issuance of Continuous Training Program and Materials on Wound Care.

[9] Anissimova, V., et al. (2018) Scoping Review of Clinical Outcomes Related to Advanced Training in Wound Care. Surgical Technology International, 33, 67-73.

[10] Lin, F., et al. (2019) Preventing Surgical Site Infections: Facilitators and Barriers to Nurses' Adherence to Clinical Practice Guidelines: A Qualitative Study. Journal of Clinical Nursing, 28, 1643-1652. https://doi.org/10.1111/jocn.14766

[11] Woldegioris, T., Bantie, G. and Getachew, H. (2019) Nurses' Knowledge and Practice Regarding Prevention of Surgical Site Infection in Bahir Dar, Northwest Ethiopia. Surgical Infections, 20, 71-77. https://doi.org/10.1089/sur.2018.081

[12] Lewis, P., et al. (2012) Design and Delivery of a Distance Education Programme: Educating Vietnamese Nurse Academics from Australia. Procedia-Social and Behavioral Sciences, 47, 1462-1468. https://doi.org/10.1016/j.sbspro.2012.06.843

[13] Tweed, C. and Tweed, M. (2008) Intensive Care Nurses' Knowledge of Pressure Ulcers: Development of an Assessment Tool and Effect of an Educational Program. American Journal of Critical Care, 17, 338-346. https://doi.org/10.4037/ajcc2008.17.4.338

[14] Sutherland-Fraser, S., et al. (2012) Peri-Operative Nurses' Knowledge and Reported Practice of Pressure Injury Risk Assessment and Prevention: A Before-After Intervention Study. BMC Nursing, 11, 25. https://doi.org/10.1186/1472-6955-11-25 
[15] Yang, C.W., et al. (2012) A Systematic Review of Retention of Adult Advanced Life Support Knowledge and Skills in Healthcare Providers. Resuscitation, 83, 1055-1060. https://doi.org/10.1016/j.resuscitation.2012.02.027

[16] Surme, Y., Kartin, P.T. and Curuk, G.N. (2018) Knowledge and Practices of Nurses Regarding Wound Healing. Journal of PeriAnesthesia Nursing, 33, 471-478. https://doi.org/10.1016/j.jopan.2016.04.143

[17] International Pain Summit of the International Association for the Study of, P. (2011) Declaration of Montreal: Declaration That Access to Pain Management Is a Fundamental Human Right. Journal of Pain and Palliative Care Pharmacotherapy, 25, 29-31. https://doi.org/10.3109/15360288.2010.547560

[18] Issa, M., Awajeh, A. and Khraisat, F. (2017) Knowledge and Attitude about Pain and Pain Management among Critical Care Nurses in a Tertiary Hospital. Journal of Intensive and Critical Care, 3, 1. https://doi.org/10.21767/2471-8505.100071

[19] Lewthwaite, B., et al. (2011) Nurses' Knowledge and Attitudes Regarding Pain Management in Hospitalized Adults. Journal of Continuing Education in Nursing, 42, 251-257. https://doi.org/10.3928/00220124-20110103-03

[20] Matthews, E. and Malcolm, C. (2007) Nurses' Knowledge and Attitudes in Pain Management Practice. The British Journal of Nursing, 16, 174-179. https://doi.org/10.12968/bjon.2007.16.3.22972

[21] Toba, H.A., Samara, A.M. and Zyoud, S.H. (2019) Nurses' Knowledge, Perceived Barriers, and Practices Regarding Cancer Pain Management: A Cross-Sectional Study from Palestine. BMC Medical Education, 19, Article No. 167.

https://doi.org/10.1186/s12909-019-1613-Z

[22] Vietnam's Ministry of Health (2011) Circular No. 07/2011/TT-BYT Issued on January 26, 2011, Regarding Instructions on Nursing Care for Patients at Hospital.

[23] Phan, T.D. and Nguyen, D.C. (2018) Assessment of Nurses' Knowledge after 6, 9, 12 Months after the Training Program on Wound Care Based on Nursing Competencies Standards at Viet Duc Hospital. Journal of Disaster Medicine and Burn Injuries, 4, 47-54.

[24] Phan, T.D., et al. (2016) Evaluating a Training Programme at Viet Duc University Hospital in Vietnam. The British Journal of Nursing, 25, S14-S21. https://doi.org/10.12968/bjon.2016.25.12.S14

[25] Mezirow, J. (1981) A Critical Theory of Adult Learning and Education. Adult Education, 32, 3-24. https://doi.org/10.1177/074171368103200101

[26] Bandura, A. (1986) The Explanatory and Predictive Scope of Self-Efficacy Theory. Journal of Social and Clinical Psychology, 4, 359-373. https://doi.org/10.1521/jscp.1986.4.3.359 